\title{
Nanoparticle Formation from a Commercial Air Freshener at Real-exposure Concentrations of Ozone
}

\author{
Thai Phuong $\mathrm{Vu}^{1,2)}$, Sun-Hwa Kim ${ }^{1)}$, Seung-Bok Lee ${ }^{1)}$, Shang-Gyoo Shim ${ }^{1)}$, Gwi-Nam Bae ${ }^{1,2), *}$ \\ and Jong Ryeul Sohn ${ }^{3)}$ \\ ${ }^{1)}$ Global Environment Center, Korea Institute of Science and Technology, Seoul 136-791, Korea \\ ${ }^{2)}$ Construction Environment Engineering, University of Science and Technology, Daejeon 305-333, Korea \\ ${ }^{3)}$ Department of Environmental Health, Korea University, Seoul 136-703, Korea \\ *Corresponding author. Tel: +82-2-958-5676, E-mail: gnbae@kist.re.kr
}

\begin{abstract}
Occupational nanomaterial exposure is an important issue in the manufacture of such products. People are also exposed to various nanoparticles in their living environments. In this study, we investigated nanoparticle formation during the reaction of ozone and volatile organic compounds (VOCs) emitted from a commercial air freshener, one of many widely used consumer products, in a $1-\mathrm{m}^{3}$ reaction chamber. The air freshener contained various VOCs, particularly terpenes. A petri dish containing $0.5 \mathrm{~mL}$ of the air freshener specimen was placed in the bottom of the chamber, and ozone was continuously injected into the center of the chamber at a flow rate of $4 \mathrm{~L} / \mathrm{min}$ with an ozone concentration of either 50,100 or 200 $\mathrm{ppb}$. Each test was conducted over a period of about $4 \mathrm{~h}$. The higher ozone concentrations produced larger secondary nanoparticles at a faster rate. The amount of ozone reacted was highly correlated with the amount of aerosol formation. Ratios of reacted ozone concentration and of formed particle mass concentration for the three injected ozone concentrations of 50,100 and $200 \mathrm{ppb}$ were similar to one other; $4.6: 1.9: 1.0$ and $4.7: 2.2: 1.0$ for ozone and aerosol mass, respectively.
\end{abstract}

Key words: Nanoparticle, Air freshener, Ozone, Volatile organic compounds, Nucleation burst, Condensational growth

\section{INTRODUCTION}

Air freshener use implies improved indoor air quality and healthier air for people to breathe. The use of air fresheners has recently been increasing. Although the volatile organic compounds (VOCs) released from air fresheners often have a pleasing aroma, numerous risks have been associated with the inhalation of such VOCs, and these risks are often not listed on any product label (Steinemann, 2009). Several VOCs are considered to be health risks and are important factors in the production of photochemical smog and secondary aerosol formation. Many studies have been conducted to investigate indoor and outdoor VOCs, the results of which detailed warnings and preventive measures to improve living environments (Steinemann, 2009; Nazaroff and Weschler, 2004; Weschler, 2000).

Some of the VOCs emitted from air fresheners can react with ozone or air contaminants to form potentially harmful secondary products (Chen and Hopke, 2009; Langer et al., 2008; Liu et al., 2004; Nazaroff and Weschler, 2004). Ozone and other oxidants may also react with the dust particles or the compounds adsorbed on them, resulting in the formation of oxidation products. New particle formation may occur at low VOC concentrations and low or zero air exchange rates (Langer et al., 2008; Sarwar and Corsi, 2007). The use of commercial air fresheners may, therefore, not improve indoor air quality but may actually contribute to increased indoor air pollution to ultimately produce adverse health effects.

Outdoor background-level ozone concentration is particularly high on hot and sunny days, and indoor ozone concentration is affected by outdoor ozone concentration from $30 \%$ to $70 \%$ (Weschler, 2000). In the National Ambient Air Quality Standard (NAAQS) of the USA, the outdoor 8-h ozone concentration limit is $75 \mathrm{ppb}$. Limonene and other VOCs react with ozone in the presence of 22-25 ppb ozone concentrations (Liu et al., 2004). Langer et al. (2008) reported that secondary particle formation occurs at a $10-20 \mathrm{ppb}$ ozone concentration and at an indoor limonene concentration of $<10 \mathrm{ppb}$. Therefore, even though an indoor ozone concentration may adhere to the standard, the levels may be sufficient to allow reactions with 


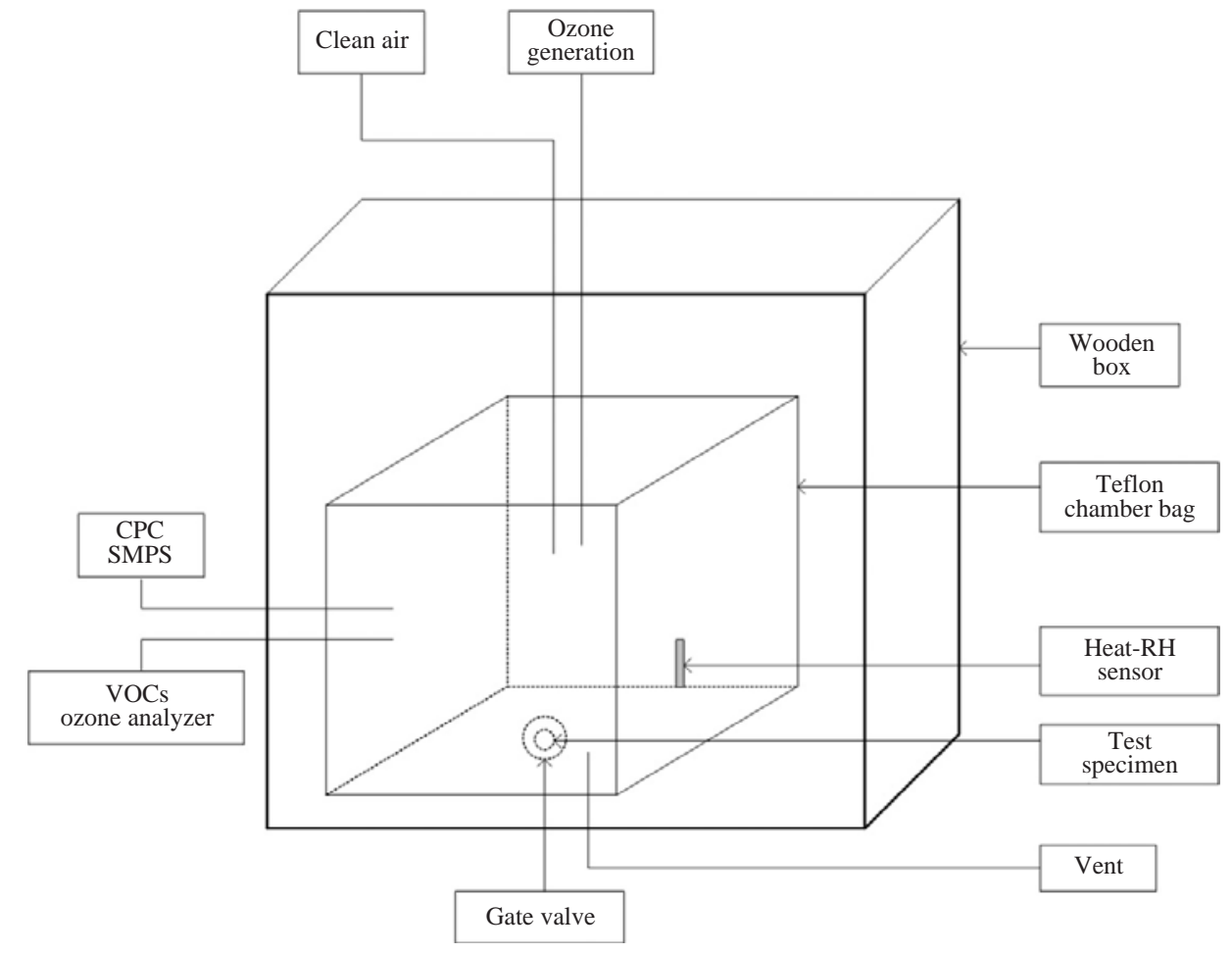

Fig. 1. Schematics of the experimental setup.
VOCs. Secondary pollutant formation depends on the concentrations of reactants such as VOCs and ozone. The evaporation of air fresheners was studied at temperatures less than $100^{\circ} \mathrm{C}$ (Aggarwala et al., 1998). The higher is the indoor temperature, the faster is the evaporation of VOCs from air fresheners, and the higher is the formed particle concentration (Lamorena and Lee, 2008).

In this study, we investigated secondary aerosol formation during the reaction of ozone and VOCs emitted from a commercial air freshener in a $1-\mathrm{m}^{3}$ reaction chamber. Three ozone concentrations $(50$, 100 and $200 \mathrm{ppb}$ ) were used to observe the effect of ozone concentration level. The VOCs contained in the air freshener were identified, and the particle number size distribution was continuously monitored using a scanning mobility particle sizer. The consumed ozone was compared with the amount of aerosols formed during the test period.

\section{EXPERIMENTAL}

As shown in Fig. 1, the experimental system consisted of a reaction chamber, ozone and pure air generators and ozone and particle monitoring instruments. The volume of the cube-shaped reaction chamber made of 2-mil (about $51 \mu \mathrm{m}$ ) FEP Teflon film was 1 $\mathrm{m}^{3}(1 \times 1 \times 1 \mathrm{~m})$, and the surface to volume ratio was $6.0 \mathrm{~m}^{-1}$. The chamber was installed in a wooden box equipped with a door in order to avoid any light disturbances from the outside. A pure air generation system (Aadco Instruments 737-15) was used to supply zero air into the reaction chamber (Bae et al., 2003). The confirmed concentrations of the impurities of $\mathrm{O}_{3}$, $\mathrm{NO}, \mathrm{NO}_{2}, \mathrm{NO}_{\mathrm{x}}$ and $\mathrm{SO}_{2}$ in zero air were $<1 \mathrm{ppb}$, and $\mathrm{CO}$ concentration was $<0.05 \mathrm{ppm}$. Limonene, $\alpha$-pinene, $\beta$-pinene and terpinene were not detected in the gas chromatograph/mass spectrometer (GC-MS, Shimadzu QP2010) analysis of the air.

Prior to each experiment, the chamber was flushed twice with pure air and ozone $(200 \mathrm{ppb})$ for $3 \mathrm{~h}$ in order to minimize the effects of bag contamination. Thereafter, background particle and ozone concentrations of the air-filled chamber were measured for $4 \mathrm{~h}$, resulting in an ozone production rate $<0.01 \mathrm{ppb} / \mathrm{min}$ and a particle mass concentration $<0.06 \mu \mathrm{g} / \mathrm{m}^{3}$.

During the experiments, the ozone concentration was monitored every one minute using a U.V. photometric $\mathrm{O}_{3}$ analyzer (TEI 49i) with an $\mathrm{O}_{3}$ lower detection limit of $1.0 \mathrm{ppb}$. The analyzer was calibrated with 700-ppb span gas. The particle number size distribution was determined using a scanning mobility particle sizer (SMPS), which consisted of an electrostatic classifier (TSI 3081) and a condensation particle counter (CPC, TSI 3010), over a scanning time of $5 \mathrm{~min}$. The 


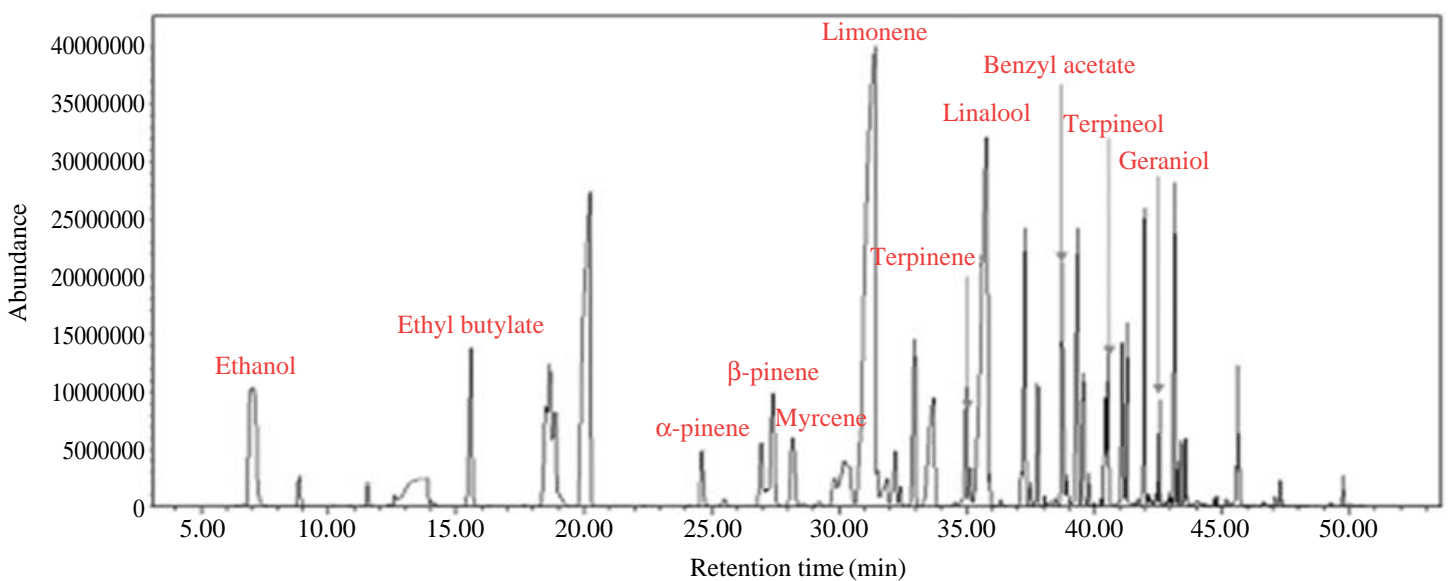

Fig. 2. Chromatogram of the volatile organic compounds emitted from the air freshener tested in this study.

aerosol and sheath flows in the electrostatic classifier were set to 0.3 and $3.0 \mathrm{~L} / \mathrm{min}$, respectively, in order to detect particles ranging from 13.8 to $723.0 \mathrm{~nm}$ in diameter. Total particle number concentration was also monitored using an ultrafine condensation particle counter (UCPC, TSI 3025) with a 1-sec response time in order to detect particles larger than $3 \mathrm{~nm}$ in size. The air temperature and relative humidity in the Teflon chamber were monitored every 5 min using a small sensor with a data logger (Sato Keiryoki SK-L200Th), the lower detection limit for relative humidity of which was $20 \%$. This data logger was placed in the bottom of the chamber.

One Teflon sampling line was connected to the $\mathrm{O}_{3}$ analyzer, and the SUS sampling line was connected to the SMPS and the UCPC. The total sampling flow rate for monitoring concentrations of particles and ozone in the chamber was controlled to be similar to the flow rate of ozone injected into the chamber. The control of inflow and outflow produced an approximate air exchange rate of $0.24 \mathrm{~h}^{-1}$.

A $0.5-\mathrm{mL}$ test specimen of a liquid-type air freshener was contained in a 50-mL glass petri dish with a diameter of $65 \mathrm{~mm}$ that was then placed in the bottom of the chamber, which was maintained at a temperature of $20 \pm 1{ }^{\circ} \mathrm{C}$ and a relative humidity of $<20 \%$. This specimen seemed to be dried out after about $2.5 \mathrm{~h}$ in the chamber at $20^{\circ} \mathrm{C}$, implying that all of the VOCs from the air freshener had been emitted by this time. Ozone injection started 4 min after the test specimen was set and occurred into the center of the chamber through the top surface using a photometric $\mathrm{O}_{3}$ calibrator (API 401). The ozone calibrator was operated at three different concentrations (50, 100 and $200 \mathrm{ppb)}$ at a flow rate of $4.0 \mathrm{~L} / \mathrm{min}$. Each experiment lasted for about $4 \mathrm{~h}$.

\section{RESULTS AND DISCUSSION}

\subsection{Volatile Organic Compounds Emitted from an Air Freshener}

A commercial liquid-type air freshener sold for home use was chosen as the tested product. A Teflon film bag $300 \mathrm{~mm}$ wide and $700 \mathrm{~mm}$ long was used to create about $10 \mathrm{~L}$ of volume through the supply of zero air. A cylindrical glass beaker containing a measured amount of liquid air freshener was inserted into the bag. The VOCs emitted from the air freshener were sampled into a Tenax TA adsorption tube for $10 \mathrm{~min}$ at a sampling flow rate of $200 \mathrm{~mL} / \mathrm{min}$. The chemical ingredients collected in the tube were desorbed using a thermal desorption system and analyzed using a GCMS. The adsorbent tubes were thermally desorbed at $300^{\circ} \mathrm{C}$ for $5 \mathrm{~min}$, and the analyzed compounds were cryogenically frozen at $-10^{\circ} \mathrm{C}$. A 60 -m fused silica capillary GC column (internal diameter $0.32 \mathrm{~mm}$; film thickness $1 \mu \mathrm{m}$ ) was used to separate the compounds. The initial GC oven temperature was set at $40^{\circ} \mathrm{C}$ for $5 \mathrm{~min}$ and then increased from $40^{\circ} \mathrm{C}$ to $80^{\circ} \mathrm{C}$ at a rate of $5^{\circ} \mathrm{C} / \mathrm{min}$. The MS was scanned in full-scan mode from $\mathrm{m} / \mathrm{z} 35$ to 350 in 0.5 -s scan intervals.

The VOC chromatogram is illustrated in Fig. 2. The air freshener contained many volatile organic compounds, such as $\alpha$-pinene, $\beta$-pinene, myrcene, limonene, terpinene, linalool, terpineol, benzyl and geraniol. Some of these VOCs are known to readily react with ozone, forming secondary indoor pollutants (Jo et al., 2008; Lamorena and Lee, 2008; Langer et al., 2008; Sarwar and Corsi, 2007; Fan et al., 2005).

\section{2 Background Level under Pure Air Reaction}

Prior to conducting the VOCs/ozone reaction, we 
needed to know the supplied ozone concentration in the chamber and its background potential to form secondary aerosol particles. A mass balance equation was considered to calculate the variation in ozone concentration in the chamber. The theoretical ozone concentration in the chamber was calculated using Eq. (1).

$$
\mathrm{V} \frac{\mathrm{dC}}{\mathrm{dt}}=\mathrm{Q}_{1} \mathrm{C}_{0}-\mathrm{Q}_{2} \mathrm{C}_{\mathrm{t}}
$$

where $\mathrm{V}=$ volume of the chamber $(\mathrm{L})$

$\mathrm{C}_{0}=$ injected ozone concentration (ppb)

$\mathrm{C}_{\mathrm{t}}=$ ozone concentration at time $\mathrm{t}(\mathrm{ppb})$

$\mathrm{Q}_{1}=$ inlet flow rate $(\mathrm{L} / \mathrm{min})$

$\mathrm{Q}_{2}=$ outlet flow rate $(\mathrm{L} / \mathrm{min})$

In this equation, it was assumed that the inlet flow rate $\left(\mathrm{Q}_{1}\right)$ was equal to the outlet flow rate $\left(\mathrm{Q}_{2}\right)$. If $\mathrm{V}$ and $\mathrm{C}_{0}$ are constant and the initial ozone concentration $(t=0)$ is zero, then the theoretical ozone concentration in the chamber at time $t$ is calculated using Eq. (2) (Jung et al., 2004).

$$
\mathrm{C}_{\mathrm{t}}=\mathrm{C}_{0}\left(1-\mathrm{e}^{-\mathrm{Qt} / \mathrm{v}}\right)
$$

The theoretical ozone concentration curves obtained using Eq. (2) for the three experimental conditions (50, 100 and $200 \mathrm{ppb}$ ) at the injected ozone flow rate of $4.0 \mathrm{~L} / \mathrm{min}$ are plotted in Fig. 3. Each experimental ozone concentration curve showed fair agreement with the theoretical values. The slightly lower experimental values might have been caused by the incomplete mixing of the ozone, loss of ozone due to adsorption to the chamber wall and reaction with the VOCs in the chamber filled with pure air. The measured ozone concentrations inside the chamber for 50,100 and $200 \mathrm{ppb}$ experiments reached 26, 50 and $108 \mathrm{ppb}$, respectively, after $4 \mathrm{~h}$.

To investigate the effect of background contamina-

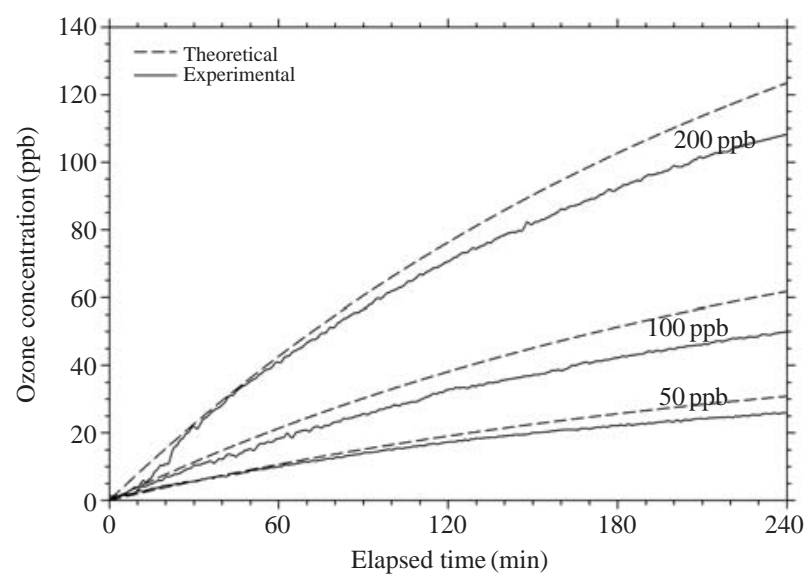

Fig. 3. Comparison of experimental and theoretical ozone concentrations. tion on the formation of secondary aerosols, we conducted experiments on the reaction of ozone with pure air. Changes in particle number and mass concentration with elapsed time are plotted in Fig. 4(a) and 4(b), respectively. Since secondary organic particles are mostly spherical (Lee et al., 2005), we calculated particle mass from the particle number size distribution data obtained using the SMPS measurements and assuming that particle density was $1 \mathrm{~g} / \mathrm{cm}^{3}$. Fig. 4(a) shows that particle formation clearly started at about 105 and 75 min for injected ozone concentrations of 100 and 200 ppb, respectively. Thereafter, secondary aerosols were continuously formed, and the particle number concentrations for 100 and $200 \mathrm{ppb}$ reached 668 and 1,798 particles $/ \mathrm{cm}^{3}$, respectively, after $240 \mathrm{~min}$. In the case of the 50-ppb ozone concentration, however, aerosol formation was not observed.

Fig. 4(b) shows that the formed particle mass also increased for both 100 and 200 ppb conditions. Particle mass concentrations due to reactions of unknown
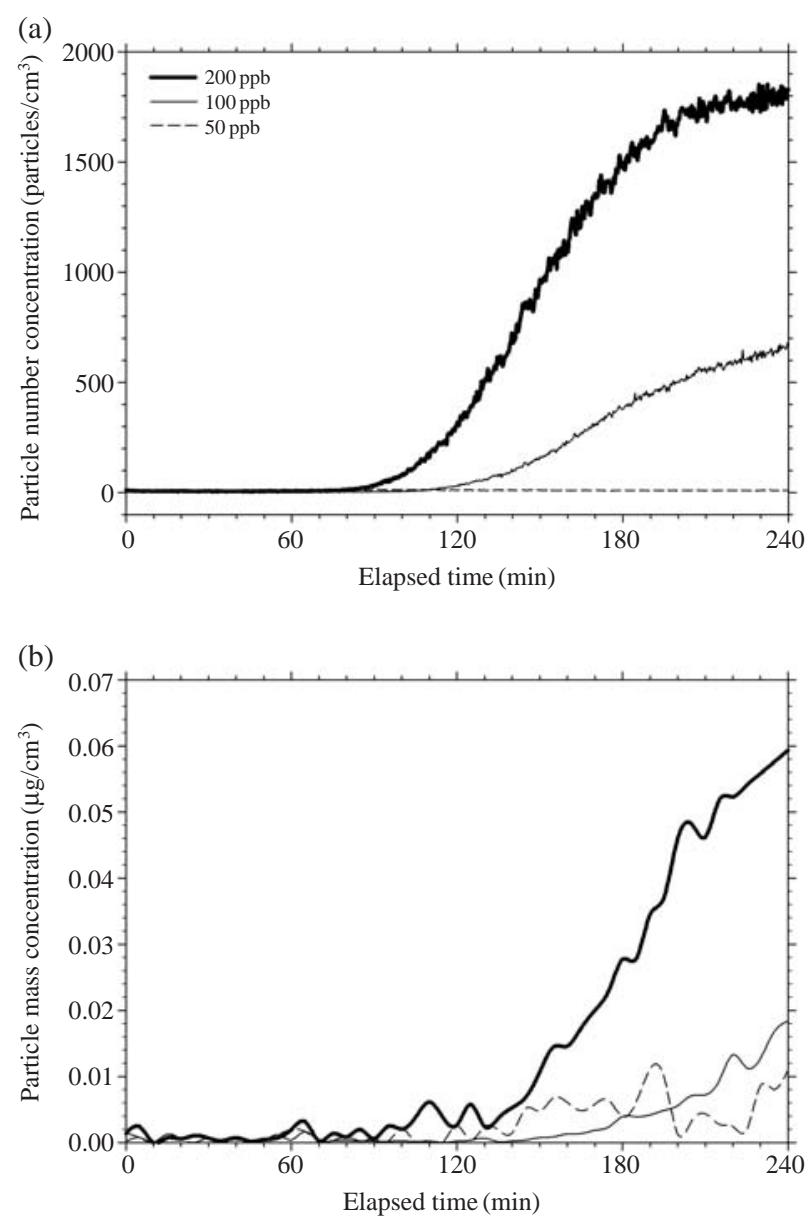

Fig. 4. Background particle formation under pure air reactions for 50, 100 and $200 \mathrm{ppb}$ ozone concentrations, (a) particle number, (b) particle mass. 
substances in pure air and ozone in the chamber were 0.02 and $0.06 \mu \mathrm{g} / \mathrm{m}^{3}$ for injected ozone concentrations of 100 and $200 \mathrm{ppb}$, respectively, after $4 \mathrm{~h}$. In the case of the 50-ppb ozone concentration, although small amounts of formed particle mass were observed after $120 \mathrm{~min}$, no increasing trend was observed and the particle mass concentration was maintained under $0.01 \mu \mathrm{g} / \mathrm{m}^{3}$. This concentration was thus considered the noise level of particle mass concentration. Thus, the concentration of formed particles was insignificant at the injected ozone concentration of $50 \mathrm{ppb}$.

\section{3 Ozone Reduction and Particle Formation under the Air Freshener Reaction}

It is well known that the reactions of VOCs/ozone form secondary aerosol particles. The amount of newly formed particles depends on various factors such as concentrations of VOCs and ozone, air temperature, relative humidity and the chemicals in the VOCs (Lamorena and Lee, 2008; Singer et al., 2006; Fan et al., 2005; Liu et al., 2004). In this study, it was observed that ozone concentration had an effect on secondary aerosol formation.

When ozone was injected into the chamber, the ozone reacted with pre-existing VOCs emitted from the test specimen. Therefore, the ozone concentrations in the presence of the air freshener specimen were lower than those in the pure air reaction, as shown in Fig. 3. Fig. 5 compares these differences among the three ozone concentration levels. As expected, the ozone concentrations in the air freshener experiment significantly deviated from those for the experiment of the pure air reaction, indicating that ozone is consumed during reaction with VOCs.

The ozone consumption rate might also have changed with elapsed time. In Fig. 5, there were no obvious

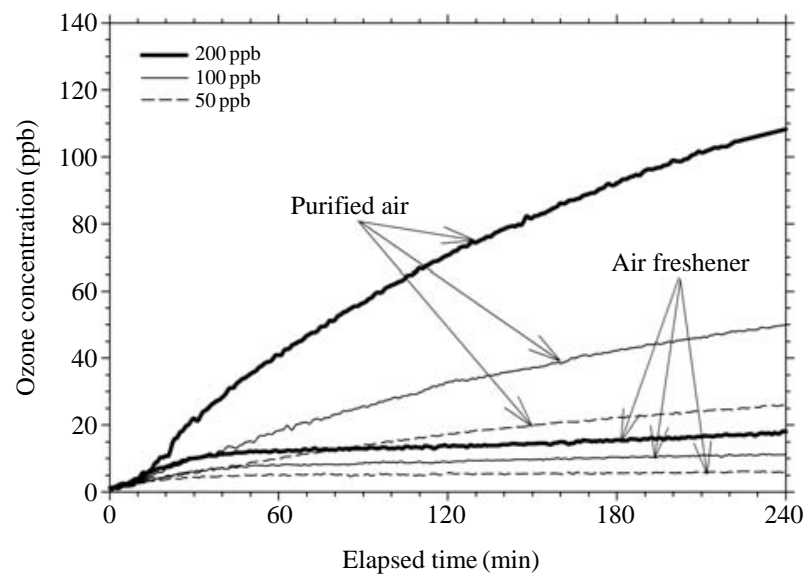

Fig. 5. Comparison of ozone concentrations between the pure air and air freshener experiments during the chemical reaction. differences between the two ozone concentration curves for the first $10 \mathrm{~min}$. Thereafter, the ozone concentrations slowly increased, resulting in significant deviations from the ozone concentration curves under the pure air reaction. Four time periods (0-10 min, 11-114 min, 115-180 min and 181-240 min) were created according to the ozone consumption rate. As shown in Table 1, ozone was heavily consumed during the second period, after which, the consumption rate decreased. The ozone consumption rate was higher at higher ozone concentration conditions. For example, ozone consumption rates for 50,100 and $200 \mathrm{ppb}$ experiments during the second period were $0.11,0.22$ and $0.54 \mathrm{ppb} /$ min, respectively. The ozone consumption rate seemed to be proportional to the injected ozone concentration in these experimental conditions. Although ozone was injected into the chamber at concentrations of 50,100 and $200 \mathrm{ppb}$, the measured ozone concentrations were significantly lower at the end of experiment, 6, 11 and $18 \mathrm{ppb}$, respectively.

Typical particle formation and the growth phenomena are shown in Fig. 6(a) and 6(b) for 200-ppb ozone concentration. Fig. 6(a) shows that nanoparticle formation began after about $10 \mathrm{~min}$. The nanoparticle concentration increased very abruptly and quickly reached its maximum peak $\left(82,285\right.$ particles $\left./ \mathrm{cm}^{3}\right)$ at about $18 \mathrm{~min}$. This rapid formation is well known as the nucleation burst phenomenon. After reaching peak concentration, the particle number concentration decreased due to both coagulation and wall loss. The coagulation effect is calculated to be comparable to the wall loss effect when the particle number concentration is about 80,000 particles $/ \mathrm{cm}^{3}$ for a particle size of about $40 \mathrm{~nm}$ (Hinds, 1999). However, the coagulation phenomenon becomes relatively unimportant when the particle concentration decreases to 50,000 particles/ $\mathrm{cm}^{3}$ or when particles grow larger than $100 \mathrm{~nm}$, because decrement in particle concentration under these conditions can be explained only by wall loss (Lee et al., 2004).

Condensable vapors formed during the reaction of ozone and VOCs contributed to nanoparticle formation in the early stage of this experiment. After the nuclea-

Table 1. Reaction rate of ozone according to the elapsed time period.

\begin{tabular}{lccc}
\hline \multirow{2}{*}{$\begin{array}{c}\text { Elapsed } \\
\text { time (min) }\end{array}$} & \multicolumn{3}{c}{ Reaction rate of ozone (ppb/min) } \\
\cline { 2 - 4 } & $50 \mathrm{ppb}$ & $100 \mathrm{ppb}$ & $200 \mathrm{ppb}$ \\
\hline $0-10$ & $\mathrm{NC}$ & $\mathrm{NC}$ & $\mathrm{NC}$ \\
$11-114$ & 0.11 & 0.22 & 0.54 \\
$115-180$ & 0.08 & 0.14 & 0.33 \\
$181-240$ & 0.06 & 0.11 & 0.29 \\
\hline
\end{tabular}

NC: not calculated 
(a)

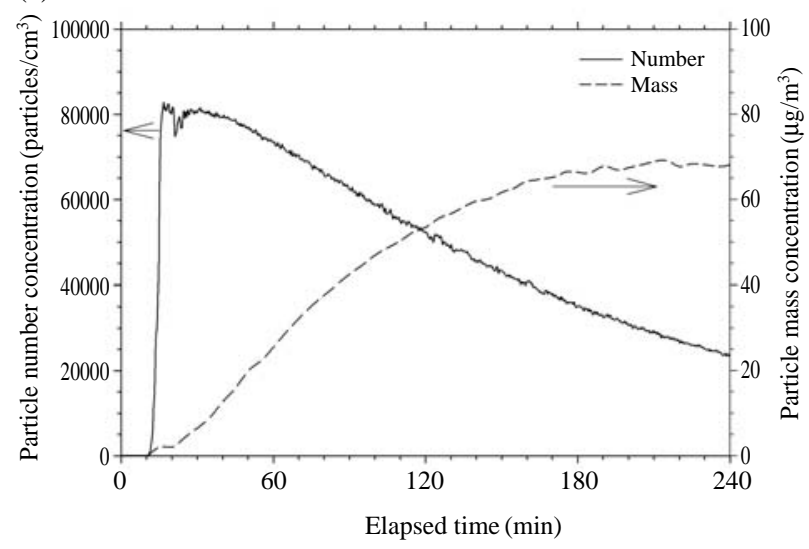

(b)

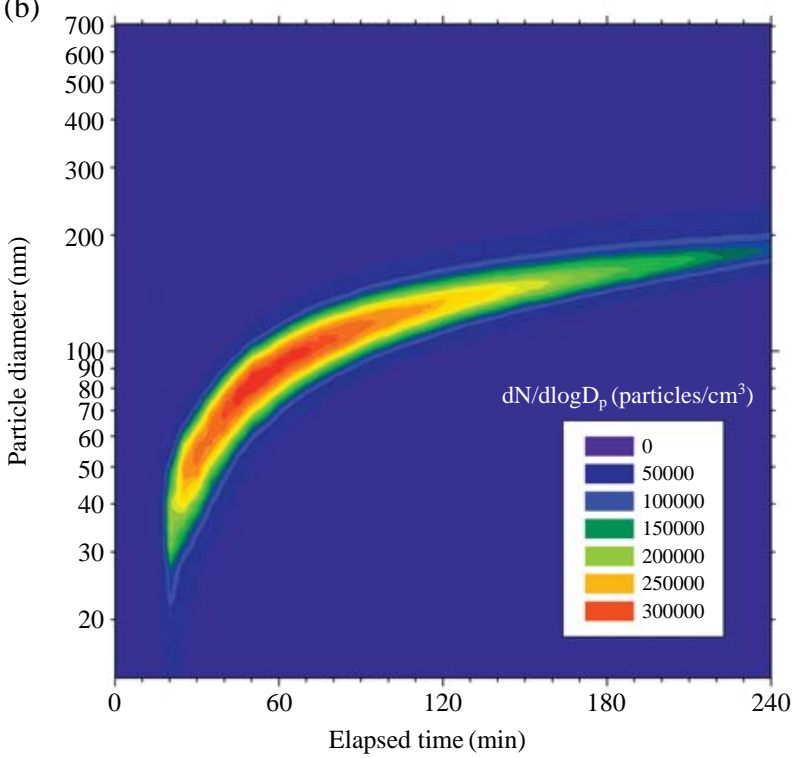

Fig. 6. Particle formation and growth phenomena due to ozone reaction with volatile organic compounds emitted from an air freshener at a 200-ppb ozone concentration, (a) particle number and mass, (b) particle size distribution.

Table 2. Effect of ozone concentration on particle production.

\begin{tabular}{lccc}
\hline \multicolumn{1}{c}{ Ozone concentration injected (ppb) } & 50 & 100 & 200 \\
\hline Ratio of ozone concentration supplied & 1 & 2 & 4 \\
Ratio of ozone concentration reacted & 1 & 1.9 & 4.6 \\
Ratio of particle mass concentration produced & 1 & 2.2 & 4.7 \\
\hline
\end{tabular}

tion burst, the nucleated nanoparticles acted as seed sites, and the condensable vapors were deposited onto the pre-existing nanoparticles. As shown in Fig. 6(b), this caused the particles to increase in size because of the condensational growth phenomenon (Heaton et al., 2007; Simchi et al., 2007; Park et al., 2002). During the condensational growth period, total particle mass concentration increased continuously, as shown in Fig.
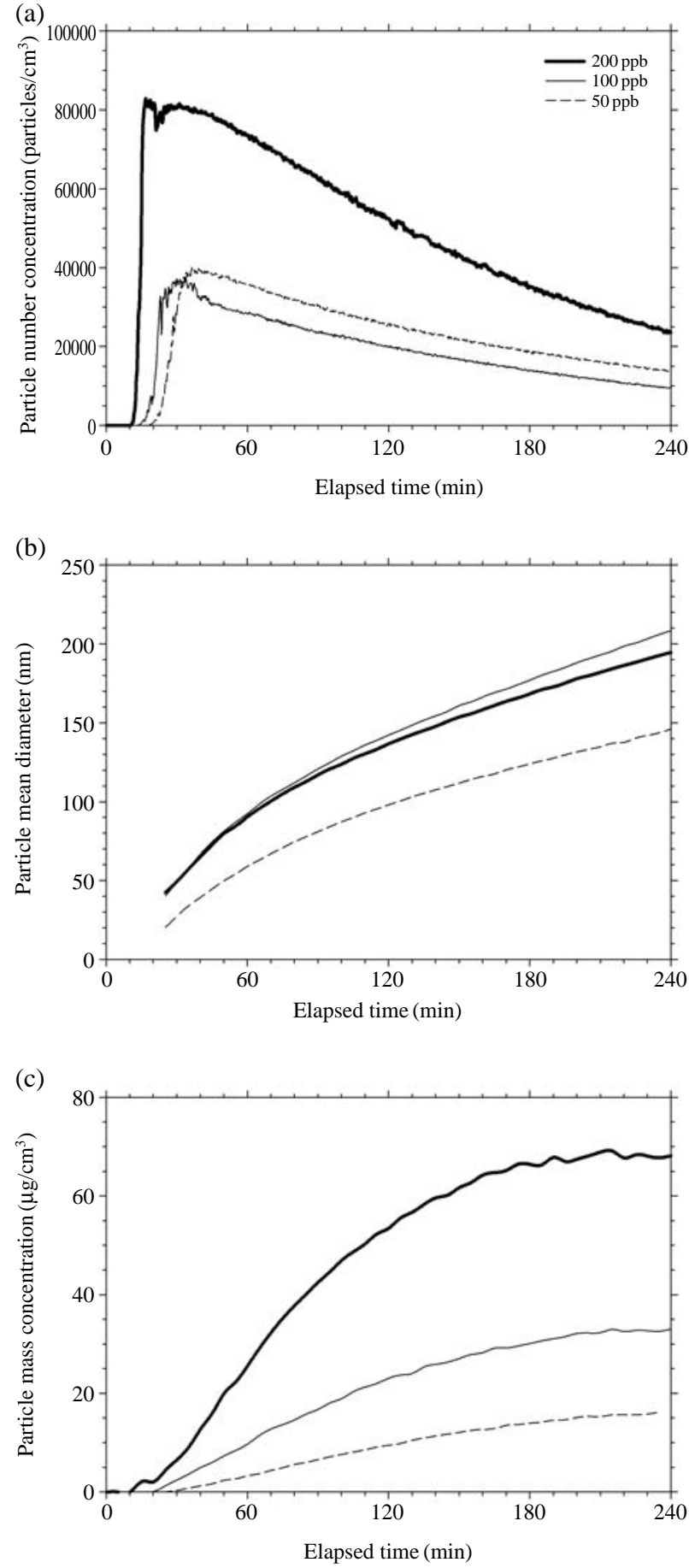

Fig. 7. Effect of ozone concentration on particle formation, (a) particle number, (b) particle mean diameter, (c) particle mass.

6(a) (Sarwar and Corsi, 2007), implying that the condensable vapors contributed continuously to the gasto-particle conversion process. Here, the particle mass concentration seemed to increase relatively rapidly until $180 \mathrm{~min}$, after which the increase was markedly 
slowed. This might be due to the drying out of the test specimen after about $150 \mathrm{~min}$. The particle mass concentration increased to $68.2 \mu \mathrm{g} / \mathrm{m}^{3}$ at $240 \mathrm{~min}$. Considering that the 24-h $\mathrm{PM}_{2.5}$ standard of NAAQS in the USA is $35 \mu \mathrm{g} / \mathrm{m}^{3}$, this concentration is not negligible for indoor environments.

\section{4 Effect of Ozone Concentration on Particle Formation}

Reactions of ozone with constituents containing VOCs emitted from an air freshener produce secondary aerosol particles. Most of these potentially reactive chemicals are terpenes or terpene-related compounds. Fan et al. (2003) reported that constituents of VOCs affect the particle mass concentration at a fixed ozone concentration. It is known that ozone concentration affects particle mass formation (Coleman et al., 2008; Lamorena and Lee, 2008). In this study, we investigated the effect of ozone on secondary aerosol formation during the reactions of ozone and VOCs in the chamber. Three low levels of ozone concentration, 50,100 and $200 \mathrm{ppb}$, were chosen to simulate realworld situations.

Fig. 7(a) shows that the nucleation burst was delayed as the ozone concentration was decreased. Namely, nanoparticle formation occurred at the elapsed times of 17,13 and $10 \mathrm{~min}$ for 50,100 and $200 \mathrm{ppb}$, respectively. The peak concentrations at 50 and $100 \mathrm{ppb}$ were about half of that at $200 \mathrm{ppb}$. Fig. 7(b) shows the variation in mean diameter of newly formed aerosol particles according to ozone concentration. The trends of particle mean diameter for 100 and $200 \mathrm{ppb}$ were similar to each other. The amount of secondary aerosol formation can be best expressed in terms of particle mass. Fig. 7(c) illustrates that particle mass concentration increased continuously and seemed to be approximately proportional to ozone concentration. Most of the particle mass (about $85 \%$ ) was produced at the elapsed time of 20-180 min. Leungsakul et al. (2005) reported that about $60 \%$ of the particle mass was produced in the initial stage. The rates of aerosol mass production were $0.09,0.19$ and $0.42 \mu \mathrm{g} / \mathrm{m}^{3} / \mathrm{min}$ between 11-180 min for ozone concentrations of 50, 100 and $200 \mathrm{ppb}$, respectively. Ratios of mass concentrations produced were similar to the ratios of ozone concentration to VOCs, as presented in Table 2. Here, the ozone concentration was a key parameter in the production of secondary particles in the presence of a fixed amount of air freshener.

\section{CONCLUSIONS}

With regard to environmental health, exposure to nanoparticles has been extensively studied. In this study, we conducted a reaction chamber experiment to quantify the amount of nanoparticles produced from the reactions of ozone and VOCs. The source of VOCs was an air freshener, a popular consumer product. Three low levels of injected ozone concentration, 50, 100 and $200 \mathrm{ppb}$, were selected to investigate the aerosol formation process.

From the pure air experiments, we found that measured ozone concentrations reached 26, 50 and $108 \mathrm{ppb}$ after $4 \mathrm{~h}$ inside the reaction chamber into which an ozone flow of the concentrations of 50, 100 and 200 ppb, respectively, was continuously injected. The amount of aerosols formed $\left(<0.06 \mu \mathrm{g} / \mathrm{m}^{3}\right)$ was negligible compared to the results $\left(>10 \mu \mathrm{g} / \mathrm{m}^{3}\right)$ of the air freshener experiments.

In the air freshener experiments, we found that ozone was significantly consumed during the reaction period. The nucleation burst occurred early at a higher ozone concentration, and the mean particle diameter increased from $<40 \mathrm{~nm}$ to $>100 \mathrm{~nm}$ due to the condensational growth phenomenon. The concentration of secondary aerosols produced seemed to be proportional to the injected ozone concentration. Namely, the rates of aerosol mass production were $0.09,0.19$ and 0.42 $\mu \mathrm{g} / \mathrm{m}^{3} / \mathrm{min}$ from $11-180 \mathrm{~min}$ for injected ozone concentrations of 50,100 and $200 \mathrm{ppb}$, respectively.

The results imply that VOCs emitted from an air freshener have the potential to produce nanoparticles under low ozone concentrations similar to those in actual living environments. Further studies are needed to quantify the VOC species emitted from consumer products and to classify the production rate of aerosol mass according to standard test methods.

\section{ACKNOWLEDGEMENTS}

This study was supported by the Korea Ministry of Environment as "The Eco-technopia 21 project."

\section{REFERENCES}

Aggarwala, P., Pereirab, S., Dollimore, D. (1998) The use of thermal analysis to study the change in air-freshener gels. Thermochimica Acta 324, 9-13.

Bae, G.N., Kim, M.C., Lee, S.B., Song, K.B., Jin, H.C., Moon, K.C. (2003) Design and performance evaluation of the KIST indoor smog chamber. Journal of the Korean Society for Atmospheric Environment 19(4), 437-449.

Chen, X., Hopke, P.K. (2009) A chamber study of secondary organic aerosol formation by linalool ozonolysis. Atmospheric Environment 43, 3935-3940.

Coleman, B.K., Lunden, M.M., Destaillats, H., Nazaroff, 
W.W. (2008) Secondary organic aerosol from ozoneinitiated reactions with terpene-rich household products. Atmospheric Environment 42, 8234-8245.

Fan, Z., Lioy, P., Weschler, C., Fiedler, N., Kipen, H., Zhang, J. (2003) Ozone-initiated reactions with mixtures of volatile organic compounds under simulated indoor conditions. Environmental Science \& Technology 37, 1811-1821.

Fan, Z., Weschler, C.J., Han, I.K., Zhang, J.J. (2005) Coformation of hydroperoxides and ultra-fine particles during the reactions of ozone with a complex VOC mixture under simulated indoor conditions. Atmospheric Environment 39, 5171-5182.

Heaton, K.J., Dreyfus, M.A., Wang, S., Johnston, M.V. (2007) Oligomers in the early stage of biogenic secondary organic aerosol formation and growth. Environmental Science \& Technology 41, 6129-6136.

Hinds, W.C. (1999) Aerosol Technology: Properties, Behavior, and Measurement of Airborne Particles. (2nd Ed.), Wiley, John \& Sons, New York, pp. 267.

Jo, W.K., Lee, J.H., Kim, M.K. (2008) Head-space, smallchamber and in-vehicle tests for volatile organic compounds (VOCs) emitted from air fresheners for the Korean market. Chemosphere 70, 1827-1834.

Jung, S.G., Lamorena, R.B., Lee, W.J., Bae, G.N., Moon, K.C., Kim, S.D. (2004) The secondary products by ozone-initiated reaction with terpenes emitted from natural paint. Indoor Environment and Technology 1(1), 88-102.

Lamorena, R.B., Lee, W. (2008) Influence of ozone concentration and temperature on ultra-fine particle and gaseous volatile organic compound formations generated during the ozone-initiated reactions with emitted terpenes from a car air freshener. Journal of Hazardous Materials 158, 471-477.

Langer, S., Moldanová, J., Arrhenius, K., Ljungström, E., Ekberg, L. (2008) Ultrafine particles produced by ozone /limonene reactions in indoor air under low/closed ventilation conditions. Atmospheric Environment 42, 4149-4159.

Lee, S.B., Bae, G.N., Moon, K.C. (2004) Aerosol wall loss in Teflon film chambers filled with ambient air. Journal of the Korean Society for Atmospheric Environment 20(E1), 35-41.

Lee, Y.M., Bae, G.N., Lee, S.B., Kim, M.C., Moon, K.C. (2005) Effect of initial toluene concentration on the photooxidation of toluene- $\mathrm{NO}_{\mathrm{x}}$-air mixture-II. Aerosol formation and growth. Journal of the Korean Society for Atmospheric Environment 21(1), 27-38.

Leungsakul, S., Jaoui, M., Kamens, R.M. (2005) Kinetic mechanism for predicting secondary organic aerosol formation from the reaction of $d$-limonene with ozone. Environmental Science \& Technology 39, 9583-9594.

Liu, X., Mason, M., Krebs, K., Sparks, L. (2004) Fullscale chamber investigation and simulation of air freshener emissions in the presence of ozone. Environmental Science \& Technology 38, 2802-2812.

Nazaroff, W.W., Weschler, C.J. (2004) Cleaning products and air fresheners: exposure to primary and secondary air pollutants. Atmospheric Environment 38, 2841-2865.

Park, S.H., Lee, K.W., Shimada, M., Okuyama, K. (2002) Change in particle size distribution of aerosol undergoing condensational growth: alternative analytical solution for the low Knudsen number regime. Journal of Aerosol Science 33, 1297-1307.

Sarwar, G., Corsi, R. (2007) The effects of ozone/limonene reactions on indoor secondary organic aerosols. Atmospheric Environment 41, 959-973.

Simchi, A., Ahmadi, R., Seyed Reihani, S.M., Mahdavi, A. (2007) Kinetics and mechanisms of nanoparticle formation and growth in vapor phase condensation process. Materials and Design 28, 850-856.

Singer, B.C., Coleman, B.K., Destaillats, H., Hodgson, A.T., Lunden, M.M., Weschler, C.J., Nazaroff, W.W. (2006) Indoor secondary pollutants from cleaning product and air freshener use in the presence of ozone. Atmospheric Environment 40, 6696-6710.

Steinemann, A.C. (2009) Fragranced consumer products and undisclosed ingredients. Environmental Impact Assessment Review 29, 32-38.

Weschler, C.J. (2000) Ozone in indoor environments: Concentration and chemistry. Indoor Air 10, 269-288.

(Received 27 September 2010, accepted 24 December 2010) 